\title{
The Association between Vaginal Dysbiosis and Reproductive Outcomes in Sub-Fertile Women Undergoing IVF-Treatment: A Systematic PRISMA Review and Meta-Analysis
}

\author{
Axel Skafte-Holm ${ }^{1} \mathbb{D}$, Peter Humaidan ${ }^{1}$, Andrea Bernabeu ${ }^{2} \mathbb{D}$, Belen Lledo ${ }^{2} \mathbb{D}$, Jørgen Skov Jensen ${ }^{3} \mathbb{D}$ \\ and Thor Haahr $1, * \mathbb{D}$ \\ 1 Department of Clinical Medicine, Aarhus University, Denmark and the Fertility Clinic Skive, \\ Skive Regional Hospital, 7800 Skive, Denmark; axel@mentor.dk (A.S.-H.); peter.humaidan@midt.rm.dk (P.H.) \\ 2 The Fertility Clinic, Instituto Bernabeu, 03016 Alicante, Spain; abernabeu@institutobernabeu.com (A.B.); \\ blledo@institutobernabeu.com (B.L.) \\ 3 Statens Serum Institute, Research Unit for Reproductive Microbiology, 2300 Copenhagen, Denmark; \\ JSJ@ssi.dk \\ * Correspondence: THOHAA@rm.dk; Tel.: +45-78445760
}

\section{check for}

updates

Citation: Skafte-Holm, A.

Humaidan, P.; Bernabeu, A.; Lledo, B.;

Jensen, J.S.; Haahr, T. The Association

between Vaginal Dysbiosis and

Reproductive Outcomes in

Sub-Fertile Women Undergoing

IVF-Treatment: A Systematic

PRISMA Review and Meta-Analysis.

Pathogens 2021, 10, 295. https://

doi.org/10.3390/pathogens10030295

Academic Editor: Milda Pleckaityte

Received: 11 December 2020

Accepted: 24 February 2021

Published: 4 March 2021

Publisher's Note: MDPI stays neutral with regard to jurisdictional claims in published maps and institutional affiliations.

Copyright: (c) 2021 by the authors. Licensee MDPI, Basel, Switzerland. This article is an open access article distributed under the terms and conditions of the Creative Commons Attribution (CC BY) license (https:// creativecommons.org/licenses/by/ $4.0 /)$.

\begin{abstract}
Recent advances in molecular microbiology have enabled refined studies of the genital tract microbiota. This constitutes the basis of the present updated systematic review and meta-analysis which investigate vaginal dysbiosis (VD) as defined by either microscopy (e.g., Nugent score for bacterial vaginosis) or molecular methods (qPCR and Next Generation Sequencing) to evaluate the impact of VD on the reproductive outcomes in women undergoing IVF-treatment. A total of 17 studies were included, comprising 3543 patients and with a VD prevalence of $18 \%$ (95\%CI 17-19). Across all methods, VD is a significant risk factor for early pregnancy loss in IVF (Relative risk (RR) $=1.71$ 95\%CI 1.29-2.27). Moreover, a predefined sub-analysis of studies using molecular methods for VD diagnosis showed a significant reduction in the clinical pregnancy rate when compared to normal vaginal microbiota patients $(\mathrm{RR}=0.5595 \% \mathrm{CI}$ 0.32-0.93). However, regardless of diagnostic methodology, VD did not significantly influence live birth rate (LBR). In conclusion, molecular tools have provided a more detailed insight into the vaginal microbiota, which may be the reason for the increased adverse effect estimates in IVF patients with molecularly defined VD. However, the quality of evidence was very low across all outcomes according to GRADE and thus, more studies are warranted to understand the impact of VD in IVF.
\end{abstract}

Keywords: bacterial vaginosis; vaginal microbiota; IVF; next generation sequencing; qPCR; clinical pregnancy rate

\section{Introduction}

Infertility is defined by an absolute failure to become pregnant, whereas subfertility refers to an inability of becoming pregnant after one year of unprotected intercourse without conceiving [1]. In this aspect, it is essential to medically examine the cause of infertility and subfertility, as it is important for fertility treatment and the outcome of assisted reproductive technology (ART). The most common reasons for infertility in the female are tubal factor, ovulation disorders and advanced female age [1,2]. Despite recent advances, numerous cases of subfertility, as well as reasons for early pregnancy losses, remain unexplained.

Whereas the vaginal microbiota and bacterial vaginosis (BV) for a long time have been investigated for preterm birth prevention [3], in recent years, the genital tract microbiota has also gained more attention in relation to early implantation, early pregnancy and live birth rate (LBR) [4,5]. Previously, it was assumed that the endometrium was a sterile cavity, but recent studies suggest the opposite-i.e., that bacteria are present in the 
endometrium $[4,6]$. This has led to the hypothesis that vaginal bacteria may ascend into the endometrium and, thus, affect reproduction [7]. Although the genital tract microbiota is a complex ecosystem of more than 200 different bacterial species [8], it is commonly accepted that a healthy genital tract microbiota is dominated by facultative anaerobic Lactobacillus spp., i.e., a Lactobacillus dominant (LD) microbiota [9]. In more detail, approximately $80 \%$ of asymptomatic reproductive age women have vaginal microbiota dominated by one of only four Lactobacillus (L.) spp.: L. crispatus, L. gasseri, L. iners and L. jensenii [10,11]. Interestingly, LD microbiota is more prevalent in pregnant women compared to non-pregnant women [12]. The reason for this is not entirely clear but could in part be explained by hormonal fluctuations influencing the vaginal microbiota. During pregnancy, elevated estrogen levels may increase the glycogen synthesis in the vaginal epithelium. Although Lactobacillus spp. do not utilize glycogen directly, the presence of the fermentation products has shown to support colonization of lactobacilli [13]. The physiological benefit of Lactobacillus spp. relates to the production of lactic acid which lowers the vaginal $\mathrm{pH}$ and protects against infection from pathogens [11,14], however, individual Lactobacillus spp. are not equally beneficial with regards to reproductive health $[12,15]$.

$\mathrm{BV}$ is the most frequent VD reported in approximately $19 \%$ of infertile women [16]. $\mathrm{BV}$ is defined as an alteration of the vaginal microbiota, resulting in a heterogeneous dysbiotic vaginal environment with reduced concentrations of Lactobacillus spp. and an increased presence of typical BV bacteria such as Gardnerella spp., Atopobium vaginae, and Mycoplasma hominis [10,17,18]. Moreover, BV may involve the presence of a polymicrobial biofilm [17] strongly adhered to the vaginal epithelium [18]. Interestingly, up to 40 percent of BV-positive women display no symptoms [19]. BV is associated with implantation failure, early miscarriage [20,21] and preterm birth [15].

Many diagnostic approaches have been used in order to diagnose BV. The Amsel Criteria, consisting of the following findings: $\mathrm{pH}>4.5$, fishy odor, presence of Clue cells, and vaginal discharge [22] is the most commonly used clinical diagnostic method. Additionally, the laboratory gold standard Nugent microscopy scoring system has been used to evaluate the abundance of Lactobacillus spp. and BV-associated bacteria [23]. Based on studies using microscopy, Van Oostrum et al. [16] published the first meta-analysis (2013) on BV in relation to reproductive outcomes in IVF patients. Subsequently, two meta-analyses, one by our group [21] (2018) and one by Singer et al. [24] (2019) have been published. Although eligibility criteria for inclusion varied in previous meta-analyses, a correlation between BV and ART-failure, including lower rates of clinical pregnancy [21,24] and an association with early spontaneous abortion [16,21] has been found.

Through the last decade, studies have enabled a shift in the diagnostic methodology of the vaginal microbiota-from microscopy to molecular based approaches [25-29]. First, many groups validated qPCR diagnostic assays according to the Nugent score BV. Secondly, the introduction of next generation sequencing (NGS) has enabled taxonomic identification of a wide range of bacterial taxa using e.g., 16S rRNA gene sequencing. This has enabled the vaginal microbiota to be stratified into community state types [30,31] and some community state types might represent VD. Molecular methods for VD diagnosis are currently being studied in a clinical context, however, among many future research subjects, the diagnostic levels for vaginal bacterial abundance in relation to clinical outcome are not well-established and the impact of temporal changes in the vaginal microbiota remains unclear. The aim of this review was to evaluate the impact of VD on the reproductive outcomes of IVF patients, stratified by molecular and microscopy methods to investigate the current state of knowledge and to inform future research.

\section{Results}

The systematic literature search identified 108 citations. A total of 70 citations were excluded based on title and an additional 27 were excluded based on abstract. Hence, a total of 11 citations were assessed for eligibility by examination of the full text. Two studies were removed due to study design $[32,33]$ and three were removed as it was not possible 
to extract pregnancy outcome data for meta-analysis [34-36]. Two studies were based on the same study population [5,29], and only the initial publication was included [5], but data on LBR was extracted from the later study [29]. A total of five studies [25-28,37] were included and added to the 12 studies $[5,20,38-47]$ in the previous version of the present systematic review and meta-analysis [21]. Overall, the present meta-analysis included a total of 17 studies, comprising 3543 IVF patients. The full selection of the studies can be seen in the Preferred Reporting Items for Systematic Reviews and Meta-Analyses (PRISMA) [48], Flow Diagram, Figure 1.
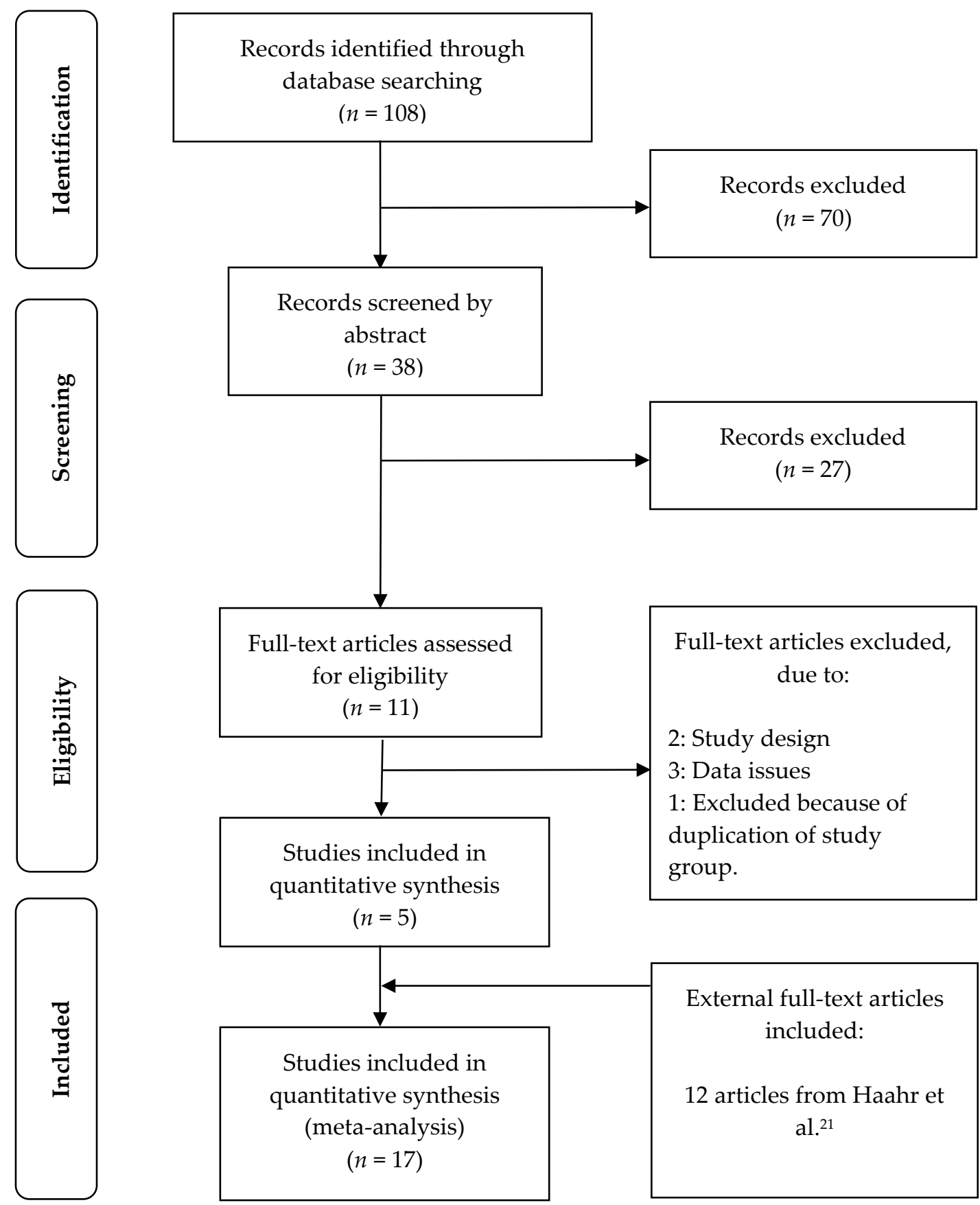

Figure 1. PRISMA Flow Diagram. 


\subsection{Data Characteristics}

A full view of individual study characteristics can be seen in Table 1. Overall, the prevalence of VD was 18\% (95\%CI 17-19) (644/3543) (Supplementary Material 3). However, a large heterogeneity of the VD prevalence was noticed in the studies, varying from $4 \%$ [47] to $44 \%$ [27].

Thirteen publications [5,20,37-47] were based on microscopy and resulted in an overall prevalence of $17 \%$ (517/3091). Two studies compared vaginal microbiota by Nugent Score with a qPCR defined abnormal vaginal microbiota (AVM), resulting in increased prevalence rates from 21 to $28 \%$ [5] and 6 to 9\% [38], respectively. Kyono et al. [27] used 16S rRNA gene sequencing and found a prevalence of $44 \%$ while Vergaro et al. [28] used a qPCR-based method, reporting a prevalence of $23 \%$. Both studies used $<90 \%$ Lactobacillus spp. as criteria to diagnose VD. Koedooder et al. [26] used an IS-pro ${ }^{\mathrm{TM}}$ technique and reported a VD prevalence of $18 \%$. This study defined an unfavorable microbiome profile by a relative Lactobacillus load $<20 \%$, relative load of L. jensenii $>35 \%$, presence of Gardnerella vaginalis or Proteobacteria $>28 \%$ of total bacterial load. Finally, one study [25] used 16S rRNA gene sequencing without defining VD. As individual participant data was shared, identification of patients with VD was performed for the present meta-analysis according to the criteria defined by Koedooder et al. listed above. This resulted in a VD prevalence of $6 \%(2 / 31)$. Overall, molecular methods (qPCR, 16S rRNA and IS-pro) resulted in a prevalence of $19 \%$ $(171 / 889)$. The prevalence ratio between microscopy and molecular methods was not significant, 0.87 (95\%CI 0.74-1.02).

By evaluating the 17 studies it became evident that the timing of the sampling differed. Seven studies $[20,38,41,42,45-47]$ performed sampling on the day of oocyte retrieval, while five studies $[27,30,40,41,44]$ performed the sampling at the time of embryo transfer, revealing a BV prevalence of $16 \%(391 / 2446)$ and $17 \%(90 / 540)$ respectively. Three studies $[5,28,45]$ performed vaginal microbiota sampling prior to IVF stimulation, presenting an overall BV prevalence of $24 \%(87 / 367)$. Finally, Kyono et al. compared a vaginal swab in different cycles and different menstrual phases [27], but no difference was observed. Moragianni et al. did not report time of sampling [37].

\subsection{Live Birth Rate (LBR)}

A total of 539 live births were recorded among 1699 patients (Supplementary Material 4). When comparing a VD to a normal vaginal microbiota in IVF-patients, data showed a relative risk (RR) of live birth per embryo transfer of $1.03\left(95 \% \mathrm{CI} 0.79-1.33 ; \mathrm{I}^{2}=28 \%\right.$ ). Subgroup analyses performed according to methodology showed a RR of $1.10(95 \% \mathrm{CI}$ $\left.0.80-1.50 ; I^{2}=32 \%\right)$ for microscopy while molecular methods revealed a RR of $0.80(95 \% \mathrm{CI}$ $0.47-1.35 ; I^{2}=32 \%$ ) (Table 2). The quality of evidence for live birth rate was very low according to The Grading of Recommendations Assessment, Development and Evaluation (GRADE) [49] (Supplementary Material 14). 
Table 1. Study characteristics. Table legend: $\mathrm{MSC}=$ modified Spiegel criteria .

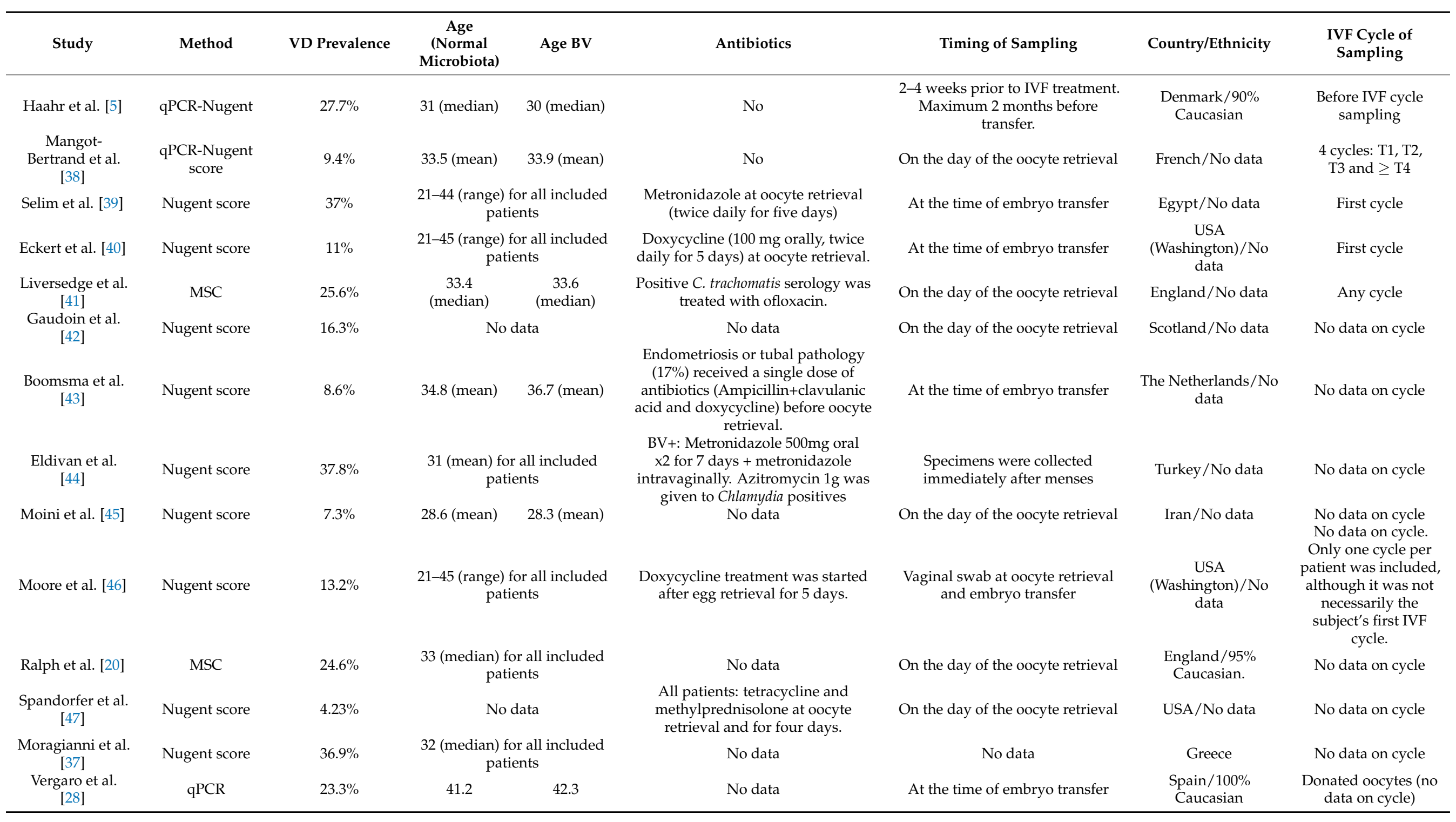


Table 1. Cont.

\begin{tabular}{|c|c|c|c|c|c|c|c|}
\hline Study & Method & VD Prevalence & $\begin{array}{c}\text { Age } \\
\text { (Normal } \\
\text { Microbiota) }\end{array}$ & Antibiotics & Timing of Sampling & Country/Ethnicity & $\begin{array}{l}\text { IVF Cycle of } \\
\text { Sampling }\end{array}$ \\
\hline $\begin{array}{c}\text { Koedooder et al. } \\
\text { [26] }\end{array}$ & IS-pro ${ }^{\mathrm{TM}}$ & $17.7 \%$ & $\begin{array}{l}\text { 20-44 (range) for all included } \\
\text { patients }\end{array}$ & No data & $\begin{array}{l}\text { Within } 2 \text { months prior to ET: } \\
\text { self-collected vaginal swab + } \\
\text { midstream urine sample before } \\
\text { IVF or IVF-ICSI start. }\end{array}$ & $\begin{array}{c}\text { The Netherlands/No } \\
\text { data }\end{array}$ & No data on cycle \\
\hline Kyono et al. [27] & 16S rRNA & $44.3 \%$ & $\begin{array}{l}37 \text { (mean) for all included } \\
\text { patients }\end{array}$ & No data & $\begin{array}{l}\text { Vaginal swab: collected in } \\
\text { different cycles and different } \\
\text { menstrual phases. }\end{array}$ & $\begin{array}{l}\text { Japan } / 100 \% \\
\text { Japanese }\end{array}$ & $\begin{array}{l}\text { Follicular phase, } \\
\text { Ovulation phase, } \\
\text { Luteal phase }\end{array}$ \\
\hline
\end{tabular}


Table 2. Relative risk on reproductive outcomes.

\begin{tabular}{|c|c|c|c|c|}
\hline Outcome & RR (CI 95\%) & $\begin{array}{l}\text { No. Of Participants } \\
\text { (Studies) }\end{array}$ & $\begin{array}{l}\text { Quality of Evidence } \\
\text { (GRADE) }\end{array}$ & $\begin{array}{l}\text { Reference \& } \\
\text { Comments }\end{array}$ \\
\hline \multicolumn{5}{|l|}{ Primary outcomes } \\
\hline Live birth rate & $1.03(0.79-1.33)$ & 1699 (9 studies) & $\oplus \ominus \ominus \ominus$ Very low * & $\begin{array}{l}\text { See Supplementary } \\
\text { Materials } 4 \text { and } 8 \text {. }\end{array}$ \\
\hline Microscopy & $1.10(0.80-1.50)$ & 1231 (6 studies) & $\oplus \ominus \ominus \ominus$ Very low * & $\begin{array}{l}\text { See Supplementary } \\
\text { Materials } 4 \text { and } 8\end{array}$ \\
\hline Molecular & $\mathbf{0 . 8 0}(0.47-1.35)$ & 543 (4 Studies) & $\oplus \ominus \ominus \ominus$ Very low * & $\begin{array}{l}\text { See Supplementary } \\
\text { Materials } 4 \text { and } 8\end{array}$ \\
\hline Early pregnancy loss & $1.71(1.29-2.27)$ & 1386 (14 studies) & $\oplus \ominus \ominus \ominus$ Very low * & $\begin{array}{l}\text { See Supplementary } \\
\text { Materials } 5 \text { and } 9 .\end{array}$ \\
\hline Microscopy & $1.61(1.17-2.20)$ & 1179 (11 studies) & $\oplus \ominus \ominus \ominus$ Very low * & $\begin{array}{l}\text { See Supplementary } \\
\text { Materials } 5 \text { and } 9 .\end{array}$ \\
\hline Molecular & $2.12(0.91-4.90)$ & 245 (4 studies) & $\oplus \ominus \ominus \ominus$ Very low * & $\begin{array}{l}\text { See Supplementary } \\
\text { Materials } 5 \text { and } 9 .\end{array}$ \\
\hline \multicolumn{5}{|l|}{ Secondary outcomes } \\
\hline $\begin{array}{l}\text { Clinical pregnancy } \\
\text { rate }\end{array}$ & $0.84(0.68-1.04)$ & 3315 (17 studies) & $\oplus \ominus \ominus \ominus$ Very low * & $\begin{array}{c}\text { See Supplementary } \\
\text { Materials } 6 \text { and } 10 . \\
\text { From Moore et al. [46] } \\
\text { we used LBR. }\end{array}$ \\
\hline Microscopy & $0.95(0.78-1.16)$ & 2573 (12 studies) & $\oplus \ominus \ominus \ominus$ Very low * & $\begin{array}{l}\text { See Supplementary } \\
\text { Materials } 6 \text { and } 10 .\end{array}$ \\
\hline Molecular & $0.55(0.32-0.93)$ & 826 (6 studies) & $\oplus \ominus \ominus \ominus$ Very low * & $\begin{array}{l}\text { See Supplementary } \\
\text { Materials } 6 \text { and } 10 . \\
\text { See Supplementary }\end{array}$ \\
\hline $\begin{array}{c}\text { Biochemical } \\
\text { pregnancy rate }\end{array}$ & $0.95(0.79-1.15)$ & 2845 (14 studies) & $\oplus \ominus \ominus \ominus$ Very low * & $\begin{array}{l}\text { Materials } 7 \text { and } 11 . \\
\text { From Moore et al. [46] } \\
\text { we used LBR. }\end{array}$ \\
\hline Microscopy & $0.98(0.78-1.23)$ & 2374 (11 studies) & $\oplus \ominus \ominus \ominus$ Very low * & $\begin{array}{l}\text { See Supplementary } \\
\text { Materials } 7 \text { and } 11 .\end{array}$ \\
\hline Molecular & $\mathbf{0 . 7 8}(0.58-1.04)$ & 555 (4 studies) & $\oplus \ominus \ominus \ominus$ Very low * & $\begin{array}{l}\text { See Supplementary } \\
\text { Materials } 7 \text { and } 11\end{array}$ \\
\hline
\end{tabular}

* Symbols according to GRADE [49]. For quality assessment see Supplementary Material 14.

\subsection{Early Pregnancy Loss}

A total of 235 early pregnancy losses were recorded among 1386 patients (Supplementary Material 5). The relative risk of early pregnancy loss per hCG positive pregnancy for VD patients undergoing IVF was $1.71\left(95 \% \mathrm{CI} 1.29-2.27 ; \mathrm{I}^{2}=0 \%\right)$ when compared to normal microbiota patients. A subgroup analysis of microscopy showed a RR of 1.61 $\left(95 \%\right.$ CI $\left.1.17-2.20 ; I^{2}=0 \%\right)$, compared to $2.12\left(95 \%\right.$ CI $\left.0.91-4.90 ; I^{2}=37 \%\right)$ when stratifying for molecular methods (Table 2). The quality of evidence on early pregnancy loss was very low according to GRADE [49] (Supplementary Material 14).

\subsection{Clinical and Biochemical Pregnancy}

A total of 1051 clinical pregnancies were recorded among 3315 patients (Supplementary Material 6). Overall results showed a RR of $0.84\left(95 \% \mathrm{CI} 0.68-1.04 ; \mathrm{I}^{2}=41 \%\right)$ per embryo transfer in clinical pregnancy rate when comparing patients with VD to patients with a normal microbiota. Subgroup analyses stratifying by molecular methods showed a significantly lower RR for clinical pregnancy per embryo transfer in VD patients, 0.55 (95\%CI 0.32-0.93; $\left.\mathrm{I}^{2}=49 \%\right)$. In contrast, when stratifying for microscopy, RR was 0.95 (95\%CI 0.78-1.16; $\mathrm{I}^{2}=22 \%$ ) for clinical pregnancy per embryo transfer.

By investigating biochemical pregnancy rate (serum HCG-positive) per embryo transfer it became evident, that no significant association was observed when comparing the two groups. An overall RR of $0.95\left(95 \% \mathrm{CI} 0.79-1.15 ; \mathrm{I}^{2}=38 \%\right)$ was found, while with 
microscopy a RR of $0.98\left(95 \%\right.$ CI $\left.0.78-1.23 ; \mathrm{I}^{2}=47 \%\right)$ was found. Molecular methods showed a RR of 0.78 (95\%CI 0.58-1.04; $\left.\mathrm{I}^{2}=0 \%\right)$ (Table 2). Overall, 1100 biochemical pregnancies were recorded among 2845 patients (Supplementary Material 7). The quality of evidence on clinical- and biochemical pregnancy was very low according to GRADE [49] (Supplementary Material 14).

\section{Discussion}

\subsection{Main Findings}

This systematic review and meta-analysis found a VD prevalence of $18 \%(95 \% \mathrm{CI}$ 17-19) among infertile patients undergoing IVF-treatment, which is in line with previous reports [16,21]. Microscopy resulted in a VD prevalence of $17 \%$, while molecular methods revealed a prevalence of $19 \%$. Although this prevalence estimate could constitute a measure of VD in the general IVF population, we generally found that the prevalence of VD differed a lot among studies which call into question the general use of this estimate for specific populations and different VD definitions. Despite a significant increase in early pregnancy loss $(\mathrm{RR}=1.7195 \% \mathrm{CI}$ 1.29-2.27), the overall meta-analysis indicated that VD did not significantly impact LBR, clinical pregnancy rates or biochemical pregnancy rates (Table 2). Interestingly, stratification for molecular diagnostic methods only, found a significant association between VD and the clinical pregnancy rate ( $R R=0.5595 \% C I$ : $0.32-0.93$ ) (Table 2). This could be interpreted as an effect of a more accurate VD diagnosis using molecular based methods. Moreover, for all other reproductive outcomes investigated herein, the effect estimates were more pronounced when using molecular based methods as compared to microscopy, albeit not statistically significant. According to GRADE [49] the quality of evidence was very low across all outcomes. Thus, additional research is needed in order draw firm conclusions regarding VD in relation to reproductive outcomes in IVF patients.

\subsection{Strengths and Limitations}

A series of eligibility criteria were prepared in order to homogenize the studies included, however, despite this effort a widespread heterogeneity was observed, including age, ethnicity, diagnostic approach, and use of antibiotics (Table 1). Five studies $[40,42,44,45,48]$ used antibiotics for either all patients or in patients with antibioticrequiring diseases, which may have biased outcomes in the respective studies as well as in this meta-analysis. However, we previously analyzed the antibiotic impact on effect estimates [5,20,21,38-47] and as none of the added studies [25-28,37] reported use of antibiotics, we did not repeat this analysis in the present study. Most studies [26-28] did not share underlying individual participant data. Compared to the estimated prevalence of VD compiling microscopy and different molecular based VD diagnostic methods, individual patient data might have resulted in an optimization of the comparison between molecular and microscopy methods.

Furthermore, large inter-study differences in VD prevalence were observed, ranging between $4 \%$ and $44 \%$. It became clear that sampling was performed at different time points during the menstrual cycle and in relation to IVF treatment (Table 1). This could have affected the prevalence of VD, as the vaginal microbiota may be influenced by hormonal fluctuations $[50,51]$.

Another limitation to this study is the fact that molecular methods do not cover the vaginal mycobiome, which potentially could impact the association observed in this study. The most common yeast, Candida albicans share some of the same pathogenesis as Gardnerella spp. [52], which might affect reproduction.

Studies based on molecular methods in comparison to microscopy are few, only covering 889 patients compared to 3091 in studies based on microscopy. Unfortunately, the present molecular methods for VD diagnosis are not uniform by definition which may be a significant contribution to the interstudy heterogeneity observed in this meta-analysis. Overall, the strength of evidence was very low on all outcomes according to GRADE [49]. 
This finding add uncertainty to the estimates, which underline the importance of additional research.

The strength of this study, however, is the addition of five new studies, which enabled this meta-analysis to be the first to present a predefined sub-analysis, covering molecular methods for detection of VD and the risk of adverse reproductive outcomes in IVF patients. This review highlights important aspects in the transformation of the diagnostic methodology in relation to BV and provides a detailed summarization, across methods, for researchers in the field.

\section{Interpretation}

Overall, three systematic reviews $[16,21,24]$ were identified in relation to this topic. Compared to the previous systematic review by our group [21], Singer et al. [24] included only six studies [5,38-42], concluding that a VD reduces the clinical pregnancy rate compared to patients with a normal vaginal microbiota (OR $=0.7095 \%$ CI 0.49-0.99) [24]. We used RR for statistical analysis, reporting that VD did not significantly impact LBR, biochemical pregnancy rates, or clinical pregnancy rates, however a significant association with early spontaneous abortion $(\mathrm{RR}=1.7195 \% \mathrm{CI} 1.29-2.27)$ was found in the overall analysis [21]. The present meta-analysis corroborates previous findings, as VD was associated with early pregnancy loss and a lower clinical pregnancy rate, yet the latter was only noticed in VD patients diagnosed by molecular methods. In our view, this is an important finding which may be due to a more accurate VD diagnosis using molecular methods.

In general, we observed a higher point prevalence of VD among molecular methods compared to microscopy. Two studies showed a numerical increase in the VD prevalence being 4\% [38] and 7\% [5] respectively both studies used a qPCR-method compared to Nugent Score. This increase was mainly caused by the dichotomization of the intermediate Nugent score patients, as previously described [21]. In contrast, two other studies [27,28] used the arbitrary cut-off level $<90 \%$ Lactobacillus spp. as a definition of VD. Based on qPCR and relative cut-offs, Vergaro et al. reported no overall association between VD among IVF patients with blastocyst transfer who achieved a live birth compared to women with no live birth. However, a significantly higher LBR was noted among women whose vaginal microbiota was dominated by L. crispatus [28]. In support, Bernabeu et al. reported a significant association between Lactobacillus-dominated microbiota (mainly L. crispatus) in IVF patients achieving biochemical pregnancy, using 16S rRNA gene sequencing [25]. Moreover, based on the IS-pro ${ }^{\mathrm{TM}}$ technique Koedooder et al. noted, that a high abundance of Lactobacillus spp. positively impacted clinical pregnancy rates. However, in their study a relatively high abundance $(>60 \%)$ of L. crispatus was shown to have a negative impact on pregnancy rates [26].

These equivocal findings indicate that studies $[27,28]$ using an arbitrary cut-off level of $<90 \%$ Lactobacillus spp., need to reconsider this cut-off, taking into account for example the total bacterial abundance and individual characteristics of different Lactobacillus spp. As an example, a recent study provided an excellent way to do this [53]. Interestingly, the relative abundance of vaginal Lactobacillus spp. is known to increase during pregnancy [54] potentially improving the development of a healthy pregnancy [25-27,40,46], albeit there is still no causal evidence to intervene on VD in pregnancy in order to improve reproductive outcome [3]. As stated earlier, Lactobacillus spp. protect against invasion and infection of opportunistic pathogens by lowering the $\mathrm{pH}$ in the vaginal tract [55]. The acidity depends on the Lactobacillus spp., as a lower $\mathrm{pH}$ was recorded in women with a high abundance of $\mathrm{L}$. crispatus compared to L. iners, L. jensenii and L. gasseri [31]. This characteristic may prevent opportunistic pathogens from ascending into the endometrium and negatively affect reproduction. Moreover, this could in fact explain the higher abundance of Lactobacillus spp. in pregnant women compared to infertile women if the hypothesis of VD mediated infertility holds true.

One explanation for the differences in VD diagnosis across studies origins in the fundamental difference between NGS and qPCR. While qPCR is a well-established method 
to identify known species, NGS provides a more advanced taxonomic identification of nearly all bacteria in a distinct microbiota. NGS provides a relative abundance measure, which may underestimate the presence of some bacterial species, due to e.g., high total concentrations of other bacterial species. For example, L. iners has a 15-fold higher concentration than L. crispatus by qPCR [29], and another study using genus specific primers did not observe statistical difference in the total number of lactobacilli comparing normal vaginal microbiota to BV [56]. This could result in a microbiota, which by NGS would have a relative abundance skewed by a high total abundance of e.g., L. iners which may "cover-up" VD bacteria such as Gardnerella spp. In fact, it was recently shown that a high total abundance of Gardnerella spp. may be underestimated by relative 16S rRNA gene sequencing [53]. Typically, BV has a significantly higher total bacterial load compared to normal vaginal microbiota [56]. For this reason, it is important to acknowledge that underestimated bacteria by relative abundances may still have a physiological effect. In contrast, the drawback of qPCR which focuses on only a few bacterial species, may be that $\mathrm{qPCR}$ does not sufficiently cover the entire vaginal microbiota of the specific patient. A future combined approach, using both NGS and qPCR to identify potential bacterial pathogens might be the way forward. Recently, a network meta-analysis was published displaying a network map which provided an overview on the relationships of bacterial species and assessment on studies providing direct evidence for diverse vaginal microbiota compositions and certain outcomes [57]. For the future this approach could be considered as this would provide a more detailed overview for the reader. However, in order to conduct such a network meta-analysis, authors of future association studies are encouraged to share underlying individual participant data.

Unquestionably, molecular methods have provided a more detailed insight into the vaginal microbiota allowing researchers to understand its complexity. Molecular methods are not uniform, and this review has highlighted the variability in defining VD. The present meta-analysis showed that despite the variability, the molecular based VD was significantly associated with clinical pregnancy after IVF treatment. This could lead to more appropriate criteria for identifying women for future intervention studies which is needed to understand whether VD diagnosis and treatment should be encouraged in IVF patients.

\section{Materials and Methods}

The present PRISMA conforming meta-analysis systematically reviewed studies investigating the vaginal microbiota in relation to selected reproductive outcomes in IVF. The analysis is a pre-planned and updated analysis of a previously published meta-analysis [21] (2018) carrying the PROSPERO registration: CRD42016050603. The PRISMA Checklist and PRISMA Statement for Reporting Systematic Reviews [58] and the MOOSE guidelines for Meta-analysis in observational studies [59] have been used for quality assessment and can be found in Supplementary Material 13. Eligibility criteria for study inclusion in this analysis were predefined and correlated with the criteria published previously [21] (Table 3). The primary outcomes of this review were LBR and early pregnancy loss. Secondary outcome measures were clinical pregnancy rate (ultrasound verified heartbeat) and biochemical pregnancy rate (hCG serum-positive pregnancies). Many studies do not provide information about early pregnancy loss and, thus, clinical pregnancies were subtracted from biochemical pregnancies (Supplementary Material 5) in order to deduct the number of early pregnancy losses. 
Table 3. Eligibility criteria.

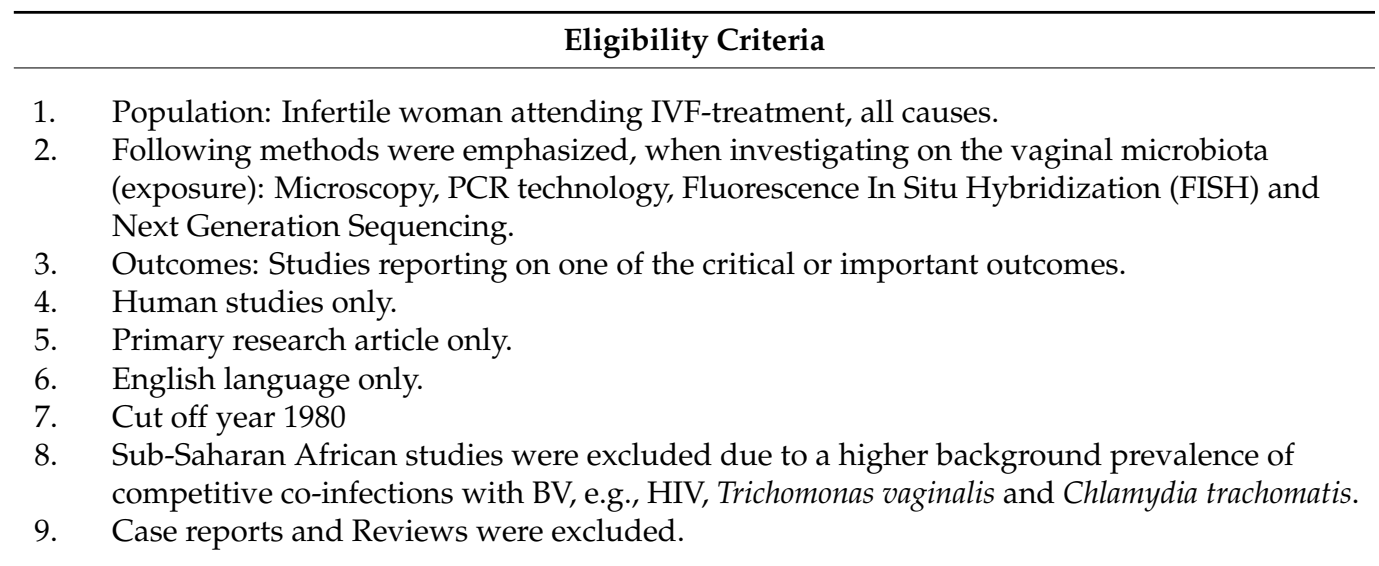

\subsection{Literature Search Strategy}

The PubMed (Medline) database was used to make an updated systematic literature search, using relevant keywords and MeSH terms (Supplementary Material 1). The previous systematic review [21] had 420 hits as of September 18, 2017. The present literature search found 528 publications as of September 27, 2020. Publications were screened by title, and subsequently by abstract by ASH and TH. If an abstract featured some of the eligibility criteria and/or outcomes, the publication was read in full. In cases of doubt, $\mathrm{PH}$ and JSJ were consulted to make a final decision on study inclusion. Additional searches in Embase, Scopus and Cochrane were conducted and generated no additional articles. For two studies, authors were contacted to provide additional data before study inclusion. One study [25] did not report individual microbiota-profiles allowing individual pregnancy outcome evaluation, but the authors who are co-authors of the present review provided relevant data for study inclusion. The authors of Moragianni et al. [37] were contacted to clarify their definition of pregnancy and the authors provided relevant data for study inclusion. Additionally, we contacted authors of three studies [34-36] but received no response and consequently their data could not be evaluated in the present meta-analysis.

\subsection{Quality of Articles}

In order to assess the quality of evidence included in the present systemic review and meta-analysis, the Newcastle-Ottawa Scale [60] was applied for each included study. Full publications were judged based on three parameters: selection of study group, comparability of groups and ascertainment of exposure or outcome. This scoring system helped identify bias and validation of the added articles [25-28,37]. Quality assessment can be found in Supplementary Material 2. Moreover, the quality of evidence was assessed using GRADE [49] for all outcomes. The basis for the evaluation can be found in Supplementary Material 14. Quality assessment of studies [5,20,38-47] included in the previous systematic review can be seen in that publication [21].

\subsection{Data Extraction and VD Definition}

Data extraction for individual studies included the following characteristics: author, analysis method, outcomes, and sample size of individual studies, and can be found in Supplementary Material 4-7. This meta-analysis chose to identify Nugent Score 0-6 as indicative of normal microbiota and 7-10 as indicative of BV/VD. Two studies [20,41] used modified Spiegel criteria [61] (MSC), which is very closely related to Nugent score. As with Nugent score, we chose to merge normal microbiota and intermediate microbiota as indicative of normal. Two studies $[5,38]$ used both Nugent Score and qPCR to assess the vaginal microbiota. Overall results were based on qPCR data from these two studies, however subgroup-analysis featured data from both methods. Recent research has emended 
the description of G. vaginalis and made discovery of three new species; G. leopoldii, G. piotii and G. swidsinskii why this study refers to Gardnerella spp. as a group [62].

The qPCR diagnosis of VD was determined based on BV with a high total abundance of Gardnerella spp. and A. vaginae as first defined by Menard et al. in pregnant women [63,64]. This qPCR diagnosis was subsequently used in a modified version by Mangot-Bertrand et al. in IVF [38]. Later, the method was further refined by our group as based on Nugent score in IVF patients [5]. In contrast to the total abundance qPCR method mentioned above, studies by Kyono et al. [27] and Vergaro et al. [28] defined VD by a non-Lactobacillus dominated microbiota (NLD: $<90 \%$ Lactobacillus spp.) and a normal microbiota defined by a Lactobacillus-dominated microbiota (LD: $>90 \%$ Lactobacillus spp.), i.e., a relative abundance method. Finally, a recent study used the 16S-23S ribosomal operon interspace region to define VD in IVF [26], the so-called IS-pro ${ }^{\mathrm{TM}}$ technique. Based on $16 \mathrm{~S}$ rRNA gene sequencing data, extradited from the study by Bernabeu et al. [25], the predictive cut-offs reported by Koedooder et al. [26] was used to define VD in that study.

Overall, this meta-analysis divided studies into two subgroups: Microscopy or molecular defined VD according to the criteria stated above. Microscopy comprised all studies based on Nugent criteria and MSC while the molecular group constituted qPCR, IS-pro ${ }^{\mathrm{TM}}$ technique and $16 \mathrm{~S}$ rRNA gene sequencing.

\subsection{Statistical Meta-Analysis}

The overall effect, relative risk (RR) with a 95\% confidence interval and Forest plot (Supplementary Material 8-11), were estimated in a random effects model, using MantelHaenszel method in REVIEW Manager version 5.3 (Cochrane, London, UK) [65]. VD prevalence's, prevalence ratio, Funnel plots with pseudo 95\% confidence limits and Egger's test (Supplementary Material 12) were computed using Stata IC Version 16.1 (Statacorp LLC, Texas, USA). Egger's test was performed to investigate potential publication bias in the GRADE [49] analysis (Supplementary Material 14). Patients lost to follow-up were excluded from analysis.

\section{Conclusions}

This systematic review and meta-analysis conclude that VD across all diagnostic methods is significantly associated with a higher early pregnancy loss rate among women undergoing IVF. In addition, stratification for molecular methods to diagnose VD revealed a significant negative impact on clinical pregnancy rates per embryo transfer. However, the quality of evidence was very low according to GRADE which warrants further research. Molecular methods have unquestionably provided a more detailed view of the vaginal microbiota and translate into more pronounced effect estimates for linking VD and reproductive outcomes in IVF patients. However, many research groups are working on various molecular diagnostics, in order to diagnose VD in IVF patients, which are not uniform. In addition, no diagnostic method has yet been proven to causally impact the reproductive outcome. Future association studies are encouraged to share underlying individual participant data in addition to the sequencing data allowing a more refined meta-analysis. This might lead to more precise evaluation of bacterial cut-off levels to diagnose VD and potentially create basis for a new gold standard using molecular methods to diagnose VD in IVF patients. Finally, future intervention trials of genital tract dysbiosis may be important to investigate causality and treatment strategies in infertility and IVF.

Supplementary Materials: The following are available online at https:/ / www.mdpi.com/2076-0 817/10/3/295/s1, Supplementary Material 1. Literature search. Supplementary Material 2. New Castle-Ottawa Quality Assessment Scale-Cohort studies Supplementary Material 3. Study Characteristic (VD prevalence) Supplementary Material 4. Live birthrate (Total) Supplementary Material 4. Live birthrate (Molecular) Supplementary Material 4. Live birthrate (Microscopy); Supplementary Material 5. Early pregnancy loss (Total) Supplementary Material 5. Early pregnancy loss (Molecular) Supplementary Material 5. Early pregnancy loss (Microscopy) Supplementary Material 6. Clinical pregnancy (Total) Supplementary Material 6. Clinical pregnancy (Molecular) Supplementary 
Material 6. Clinical pregnancy (Microscopy) Supplementary Material 7. Biochemical pregnancy (Total) Supplementary Material 7. Biochemical pregnancy (Molecular) Supplementary Material 7. Biochemical pregnancy (Microscopy) Supplementary material 8. Forest plot. Live birth rate (Total) Supplementary material 8. Forest plot. Live birth rate (Molecular) Supplementary Material 8. Forest plot. Live birth rate (Microscopy) Supplementary Material 9. Forest plot. Early pregnancy loss (Total) Supplementary material 9. Forest plot. Early pregnancy loss (Molecular) Supplementary Material 9. Forest plot. Early pregnancy loss (Microscopy) Supplementary Material 10. Forest plot. Clinical pregnancy (Total) Supplementary Material 10. Forest plot. Clinical pregnancy (Molecular) Supplementary Material 10. Forest plot. Clinical pregnancy (Microscopy) Supplementary material 11. Forest plot. Biochemical pregnancy (Total) Supplementary Material 11. Forest plot. Biochemical pregnancy (Molecular) Supplementary Material 11. Forest plot. Biochemical pregnancy (Microscopy) Supplementary Material 12. Funnel plot. Supplementary Material 13. Moose guidelines and PRISMA Guideline. Supplementary Material 14. GRADE. Quality of evidence.

Author Contributions: Conceptualization, P.H. and T.H.; Methodology, A.S.-H. and T.H.; Software, A.S.-H.; Validation, A.S.-H. and T.H.; Formal Analysis, A.S.-H.; Investigation, A.S.-H.; Resources, P.H.; Data Curation, A.S.-H.; Writing-Original Draft Preparation, A.S.-H.; Writing-Review \& Editing, P.H., T.H., A.B., B.L., J.S.J.; Visualization, A.S.-H. All authors have read and agreed to the published version of the manuscript.

Funding: This research received no external funding.

Institutional Review Board Statement: Not applicable.

Informed Consent Statement: Not applicable.

Data Availability Statement: The data presented in this study are available in Supplementary Materials 1-14.

Conflicts of Interest: Outside this study, TH has received honoraria for lectures from Ferring, IBSA, Besins and Merck. PH received unrestricted research grants from MSD, Merck, and Ferring as well as honoraria for lectures from MSD, Merck, Gedeon-Richter, Theramex, and IBSA. JSJ has received speaker's fee from Hologic, BD, SpeeDx, and Cepheid and serves scientific advisory board of Roche Molecular Systems, Abbott Molecular, and Cepheid. PH, TH and JSJ received an unrestricted research grant from Osel inc. which produces LACTIN-V, a live biotherapeutic product with Lactobacillus crispatus. $\mathrm{PH}$ and $\mathrm{TH}$ are listed as inventors in an international patent application (PCT/UK2018/040882) involving “Use of vaginal lactobacilli for improving the success rate of in vitro fertilization".

\section{References}

1. Evers, J.L. Female subfertility. Lancet 2002, 360, 151-159. [CrossRef]

2. Thurston, L.; Abbara, A.; Dhillo, W.S. Investigation and management of subfertility. J. Clin. Pathol. 2019, 72, 579-587. [CrossRef]

3. Haahr, T.; Ersbøll, A.S.; Karlsen, M.A.; Svare, J.; Sneider, K.; Hee, L.; Weile, L.K.; Ziobrowska-Bech, A.; Østergaard, C.; Jensen, J.S.; et al. Treatment of bacterial vaginosis in pregnancy in order to reduce the risk of spontaneous preterm delivery-A clinical recommendation. Acta Obstet. Gynecol. Scand. 2016, 95, 850-860. [CrossRef]

4. Moreno, I.; Codoner, F.M.; Vilella, F.; Valbuena, D.; Martinez-Blanch, J.F.; Jimenez-Almazan, J.; Alonso, R.; Alama, P.; Remohi, J.; Pellicer, A.; et al. Evidence that the endometrial microbiota has an effect on implantation success or failure. Am. J. Obstet. Gynecol. 2016, 215, 684-703. [CrossRef]

5. Haahr, T.; Jensen, J.S.; Thomsen, L.; Duus, L.; Rygaard, K.; Humaidan, P. Abnormal vaginal microbiota may be associated with poor reproductive outcomes: A prospective study in IVF patients. Hum. Reprod. 2016, 31, 795-803. [CrossRef]

6. Mitchell, C.M.; Haick, A.; Nkwopara, E.; Garcia, R.; Rendi, M.; Agnew, K.; Fredricks, D.N.; Eschenbach, D. Colonization of the upper genital tract by vaginal bacterial species in nonpregnant women. Am. J. Obstet. Gynecol. 2015, 212, e611-e619. [CrossRef]

7. Haahr, T.; Freiesleben, N.C.; Pinborg, A.; Nielsen, H.S.; Hartvig, V.; Mikkelsen, A.L.; Parks, T.; Uldbjerg, N.; Jensen, J.S.; Humaidan, P. Effect of clindamycin and a live biotherapeutic on the reproductive outcomes of IVF patients with abnormal vaginal microbiota: Protocol for a double-blind, placebo-controlled multicentre trial. BMJ Open 2020, 10, e035866. [CrossRef] [PubMed]

8. Mendling, W. Vaginal Microbiota. Adv. Exp. Med. Biol. 2016, 902, 83-93. [CrossRef]

9. Donati, L.; Di Vico, A.; Nucci, M.; Quagliozzi, L.; Spagnuolo, T.; Labianca, A.; Bracaglia, M.; Ianniello, F.; Caruso, A.; Paradisi, G. Vaginal microbial flora and outcome of pregnancy. Arch. Gynecol. Obstet. 2010, 281, 589-600. [CrossRef]

10. Lamont, R.F.; Sobel, J.D.; Akins, R.A.; Hassan, S.S.; Chaiworapongsa, T.; Kusanovic, J.P.; Romero, R. The vaginal microbiome: New information about genital tract flora using molecular based techniques. BJOG Int. J. Obstet. Gynaecol. 2011, 118, 533-549. [CrossRef] 
11. Witkin, S.S.; Linhares, I.M. Why do lactobacilli dominate the human vaginal microbiota? BJOG Int. J. Obstet. Gynaecol. 2017, 124, 606-611. [CrossRef] [PubMed]

12. Serrano, M.G.; Parikh, H.I.; Brooks, J.P.; Edwards, D.J.; Arodz, T.J.; Edupuganti, L.; Huang, B.; Girerd, P.H.; Bokhari, Y.A.; Bradley, S.P.; et al. Racioethnic diversity in the dynamics of the vaginal microbiome during pregnancy. Nat. Med. 2019, 25, $1001-1011$. [CrossRef]

13. Spear, G.T.; French, A.L.; Gilbert, D.; Zariffard, M.R.; Mirmonsef, P.; Sullivan, T.H.; Spear, W.W.; Landay, A.; Micci, S.; Lee, B.H.; et al. Human $\alpha$-amylase present in lower-genital-tract mucosal fluid processes glycogen to support vaginal colonization by Lactobacillus. J. Infect. Dis. 2014, 210, 1019-1028. [CrossRef]

14. Gong, Z.; Luna, Y.; Yu, P.; Fan, H. Lactobacilli inactivate Chlamydia trachomatis through lactic acid but not H2O2. PLoS ONE 2014, 9, e107758. [CrossRef] [PubMed]

15. Fettweis, J.M.; Serrano, M.G.; Brooks, J.P.; Edwards, D.J.; Girerd, P.H.; Parikh, H.I.; Huang, B.; Arodz, T.J.; Edupuganti, L.; Glascock, A.L.; et al. The vaginal microbiome and preterm birth. Nat. Med. 2019, 25, 1012-1021. [CrossRef] [PubMed]

16. van Oostrum, N.; De Sutter, P.; Meys, J.; Verstraelen, H. Risks associated with bacterial vaginosis in infertility patients: A systematic review and meta-analysis. Hum. Reprod. 2013, 28, 1809-1815. [CrossRef]

17. Swidsinski, A.; Mendling, W.; Loening-Baucke, V.; Ladhoff, A.; Swidsinski, S.; Hale, L.P.; Lochs, H. Adherent biofilms in bacterial vaginosis. Obstet. Gynecol. 2005, 106, 1013-1023. [CrossRef]

18. Castro, J.; Machado, D.; Cerca, N. Unveiling the role of Gardnerella vaginalis in polymicrobial Bacterial Vaginosis biofilms: The impact of other vaginal pathogens living as neighbors. ISME J. 2019, 13, 1306-1317. [CrossRef]

19. Klebanoff, M.A.; Schwebke, J.R.; Zhang, J.; Nansel, T.R.; Yu, K.F.; Andrews, W.W. Vulvovaginal symptoms in women with bacterial vaginosis. Obstet. Gynecol. 2004, 104, 267-272. [CrossRef]

20. Ralph, S.G.; Rutherford, A.J.; Wilson, J.D. Influence of bacterial vaginosis on conception and miscarriage in the first trimester: Cohort study. BMJ (Clin. Res. Ed.) 1999, 319, 220-223. [CrossRef]

21. Haahr, T.; Zacho, J.; Brauner, M.; Shathmigha, K.; Skov Jensen, J.; Humaidan, P. Reproductive outcome of patients undergoing in vitro fertilisation treatment and diagnosed with bacterial vaginosis or abnormal vaginal microbiota: A systematic PRISMA review and meta-analysis. BJOG Int. J. Obstet. Gynaecol. 2019, 126, 200-207. [CrossRef]

22. Amsel, R.; Totten, P.A.; Spiegel, C.A.; Chen, K.C.; Eschenbach, D.; Holmes, K.K. Nonspecific vaginitis. Diagnostic criteria and microbial and epidemiologic associations. Am. J. Med. 1983, 74, 14-22. [CrossRef]

23. Nugent, R.P.; Krohn, M.A.; Hillier, S.L. Reliability of diagnosing bacterial vaginosis is improved by a standardized method of gram stain interpretation. J. Clin. Microbiol. 1991, 29, 297-301. [CrossRef]

24. Singer, M.; Borg, M.; Ouburg, S.; Morre, S.A. The relation of the vaginal microbiota to early pregnancy development during in vitro fertilization treatment-A meta-analysis. J. Gynecol. Obstet. Hum. Reprod. 2019, 48, 223-229. [CrossRef]

25. Bernabeu, A.; Lledo, B.; Diaz, M.C.; Lozano, F.M.; Ruiz, V.; Fuentes, A.; Lopez-Pineda, A.; Moliner, B.; Castillo, J.C.; Ortiz, J.A.; et al. Effect of the vaginal microbiome on the pregnancy rate in women receiving assisted reproductive treatment. J. Assist. Reprod. Genet. 2019, 36, 2111-2119. [CrossRef]

26. Koedooder, R.; Singer, M.; Schoenmakers, S.; Savelkoul, P.H.M.; Morre, S.A.; de Jonge, J.D.; Poort, L.; Cuypers, W.; Beckers, N.G.M.; Broekmans, F.J.M.; et al. The vaginal microbiome as a predictor for outcome of in vitro fertilization with or without intracytoplasmic sperm injection: A prospective study. Hum. Reprod. 2019, 34, 1042-1054. [CrossRef]

27. Kyono, K.; Hashimoto, T.; Nagai, Y.; Sakuraba, Y. Analysis of endometrial microbiota by $16 \mathrm{~S}$ ribosomal RNA gene sequencing among infertile patients: A single-center pilot study. Reprod. Med. Biol. 2018, 17, 297-306. [CrossRef] [PubMed]

28. Vergaro, P.; Tiscornia, G.; Barragan, M.; Garcia, D.; Rodriguez, A.; Santalo, J.; Vassena, R. Vaginal microbiota profile at the time of embryo transfer does not affect live birth rate in IVF cycles with donated oocytes. Reprod. Biomed. Online 2019, 38, 883-891. [CrossRef]

29. Haahr, T.; Humaidan, P.; Elbaek, H.O.; Alsbjerg, B.; Laursen, R.J.; Rygaard, K.; Johannesen, T.B.; Andersen, P.S.; Ng, K.L.; Jensen, J.S. Vaginal Microbiota and In Vitro Fertilization Outcomes: Development of a Simple Diagnostic Tool to Predict Patients at Risk of a Poor Reproductive Outcome. J. Infect. Dis. 2019, 219, 1809-1817. [CrossRef]

30. France, M.T.; Ma, B.; Gajer, P.; Brown, S.; Humphrys, M.S.; Holm, J.B.; Waetjen, L.E.; Brotman, R.M.; Ravel, J. VALENCIA: A nearest centroid classification method for vaginal microbial communities based on composition. Microbiome 2020, 8, 166. [CrossRef]

31. Ravel, J.; Gajer, P.; Abdo, Z.; Schneider, G.M.; Koenig, S.S.; McCulle, S.L.; Karlebach, S.; Gorle, R.; Russell, J.; Tacket, C.O.; et al. Vaginal microbiome of reproductive-age women. Proc. Natl. Acad. Sci. USA 2011, 108, 4680-4687. [CrossRef] [PubMed]

32. Babu, G.; Singaravelu, B.G.; Srikumar, R.; Reddy, S.V.; Kokan, A. Comparative Study on the Vaginal Flora and Incidence of Asymptomatic Vaginosis among Healthy Women and in Women with Infertility Problems of Reproductive Age. J. Clin. Diagn. Res. JCDR 2017, 11, Dc18-Dc22. [CrossRef] [PubMed]

33. Amato, V.; Papaleo, E.; Pasciuta, R.; Vigano, P.; Ferrarese, R.; Clementi, N.; Sanchez, A.M.; Quaranta, L.; Burioni, R.; Ambrosi, A.; et al. Differential Composition of Vaginal Microbiome, but Not of Seminal Microbiome, Is Associated With Successful Intrauterine Insemination in Couples With Idiopathic Infertility: A Prospective Observational Study. Open Forum Infect. Dis. 2020, 7, ofz525. [CrossRef]

34. Kong, Y.; Liu, Z.; Shang, Q.; Gao, Y.; Li, X.; Zheng, C.; Deng, X.; Chen, T. The Disordered Vaginal Microbiota Is a Potential Indicator for a Higher Failure of in vitro Fertilization. Front. Med. 2020, 7, 217. [CrossRef] [PubMed] 
35. Riganelli, L.; Iebba, V.; Piccioni, M.; Illuminati, I.; Bonfiglio, G.; Neroni, B.; Calvo, L.; Gagliardi, A.; Levrero, M.; Merlino, L.; et al. Structural Variations of Vaginal and Endometrial Microbiota: Hints on Female Infertility. Front. Cell. Infect. Microbiol. 2020, 10, 350. [CrossRef] [PubMed]

36. Štšepetova, J.; Baranova, J.; Simm, J.; Parm, Ü.; Rööp, T.; Sokmann, S.; Korrovits, P.; Jaagura, M.; Rosenstein, K.; Salumets, A.; et al. The complex microbiome from native semen to embryo culture environment in human in vitro fertilization procedure. Reprod. Biol. Endocrinol. RBE 2020, 18, 3. [CrossRef]

37. Moragianni, D.; Dryllis, G.; Andromidas, P.; Kapeta-Korkouli, R.; Kouskouni, E.; Pessach, I.; Papalexis, P.; Kodonaki, A.; Athanasiou, N.; Pouliakis, A.; et al. Genital tract infection and associated factors affect the Reprod. outcome in fertile females and females undergoing in vitro fertilization. Biomed. Rep. 2019, 10, 231-237. [CrossRef]

38. Mangot-Bertrand, J.; Fenollar, F.; Bretelle, F.; Gamerre, M.; Raoult, D.; Courbiere, B. Molecular diagnosis of bacterial vaginosis: Impact on IVF outcome. Eur. J. Clin. Microbiol. Infect. Dis. 2013, 32, 535-541. [CrossRef]

39. Selim, S.A.; El Alfy, S.M.; Aziz, M.H.; Mohamed, H.M.; Alasbahi, A.A. Effective of metronidazole to bacterial flora in vagina and the impact of microbes on live birth rate during intracytoplasmic sperm injection (ICSI). Arch. Gynecol. Obstet. 2011, 284, 1449-1453. [CrossRef]

40. Eckert, L.O.; Moore, D.E.; Patton, D.L.; Agnew, K.J.; Eschenbach, D.A. Relationship of vaginal bacteria and inflammation with conception and early pregnancy loss following in-vitro fertilization. Infect. Dis. Obstet. Gynecol. 2003, 11, 11-17. [CrossRef] [PubMed]

41. Liversedge, N.H.; Turner, A.; Horner, P.J.; Keay, S.D.; Jenkins, J.M.; Hull, M.G. The influence of bacterial vaginosis on in-vitro fertilization and embryo implantation during assisted reproduction treatment. Hum. Reprod. 1999, 14, 2411-2415. [CrossRef]

42. Gaudoin, M.; Rekha, P.; Morris, A.; Lynch, J.; Acharya, U. Bacterial vaginosis and past chlamydial infection are strongly and independently associated with tubal infertility but do not affect in vitro fertilization success rates. Fertil. Steril. 1999, 72, 730-732. [CrossRef]

43. Boomsma, C.M.; Kavelaars, A.; Bozkurt, N.; Eijkemans, M.J.; Fauser, B.C.; Heijnen, C.J.; Macklon, N.S. Is bacterial vaginosis associated with a pro-inflammatory cytokine profile in endometrial secretions of women undergoing IVF? Reprod. Biomed. Online 2010, 21, 133-141. [CrossRef]

44. Eldivan, O.; Evliyaoglu, O.; Ersoy, E.; Aksu, G.; Dilbaz, S.; Goktolga, U. Does screening for vaginal infection have an impact on pregnancy rates in intracytoplasmic sperm injection cycles? Turk. J. Obstet. Gynecol. 2016, 13, 11-15. [CrossRef]

45. Moini, A.; Mohammadi Yeganeh, L.; Shiva, M.; Ahmadieh, M.; Salman Yazdi, R.; Hasani, F.; Bagheri Lankarani, N.; Sanati, A. Bacterial vaginosis and the risk of early miscarriage in women undergoing intracytoplasmic sperm injection cycles: A prospective cohort study. Hum. Fertil. 2018, 21, 263-268. [CrossRef]

46. Moore, D.E.; Soules, M.R.; Klein, N.A.; Fujimoto, V.Y.; Agnew, K.J.; Eschenbach, D.A. Bacteria in the transfer catheter tip influence the live-birth rate after in vitro fertilization. Fertil. Steril. 2000, 74, 1118-1124. [CrossRef]

47. Spandorfer, S.D.; Neuer, A.; Giraldo, P.C.; Rosenwaks, Z.; Witkin, S.S. Relationship of abnormal vaginal flora, proinflammatory cytokines and idiopathic infertility in women undergoing IVF. J. Reprod. Med. 2001, 46, 806-810.

48. Moher, D.; Liberati, A.; Tetzlaff, J.; Altman, D.G. Preferred reporting items for systematic reviews and meta-analyses: The PRISMA statement. PLoS Med. 2009, 6, e1000097. [CrossRef]

49. Holger Schünemann, J.B. Gordon Guyatt, and Andrew Oxman GRADE Handbook. Available online: https://gdt.gradepro.org/ app/handbook/handbook.html (accessed on 20 January 2021).

50. Hyman, R.W.; Herndon, C.N.; Jiang, H.; Palm, C.; Fukushima, M.; Bernstein, D.; Vo, K.C.; Zelenko, Z.; Davis, R.W.; Giudice, L.C. The dynamics of the vaginal microbiome during infertility therapy with in vitro fertilization-embryo transfer. J. Assist. Reprod. Genet. 2012, 29, 105-115. [CrossRef] [PubMed]

51. Brooks, J.P.; Edwards, D.J.; Blithe, D.L.; Fettweis, J.M.; Serrano, M.G.; Sheth, N.U.; Strauss, J.F., 3rd; Buck, G.A.; Jefferson, K.K. Effects of combined oral contraceptives, depot medroxyprogesterone acetate and the levonorgestrel-releasing intrauterine system on the vaginal microbiome. Contraception 2017, 95, 405-413. [CrossRef]

52. Kalia, N.; Singh, J.; Kaur, M. Microbiota in vaginal health and pathogenesis of recurrent vulvovaginal infections: A critical review. Ann. Clin. Microbiol. Antimicrob. 2020, 19, 5. [CrossRef] [PubMed]

53. Tettamanti Boshier, F.A.; Srinivasan, S.; Lopez, A.; Hoffman, N.G.; Proll, S.; Fredricks, D.N.; Schiffer, J.T. Complementing $16 S$ rRNA Gene Amplicon Sequencing with Total Bacterial Load To Infer Absolute Species Concentrations in the Vaginal Microbiome. Msystems 2020, 5. [CrossRef]

54. MacIntyre, D.A.; Chandiramani, M.; Lee, Y.S.; Kindinger, L.; Smith, A.; Angelopoulos, N.; Lehne, B.; Arulkumaran, S.; Brown, R.; Teoh, T.G.; et al. The vaginal microbiome during pregnancy and the postpartum period in a European population. Sci. Rep. 2015, 5, 8988. [CrossRef]

55. Witkin, S.S.; Linhares, I.M.; Giraldo, P. Bacterial flora of the female genital tract: Function and immune regulation. Best Pract. Res. Clin. Obstet. Gynaecol. 2007, 21, 347-354. [CrossRef]

56. Oerlemans, E.F.M.; Wuyts, S.; Bellen, G.; Wittouck, S.; De Boeck, I.; Ruban, K.; Allonsius, C.N.; van den Broek, M.F.L.; Donders, G.G.G.; Lebeer, S. The Dwindling Microbiota of Aerobic Vaginitis, an Inflammatory State Enriched in Pathobionts with Limited TLR Stimulation. Diagnostics 2020, 10, 879. [CrossRef] 
57. Norenhag, J.; Du, J.; Olovsson, M.; Verstraelen, H.; Engstrand, L.; Brusselaers, N. The vaginal microbiota, human papillomavirus and cervical dysplasia: A systematic review and network meta-analysis. BJOG Int. J. Obstet. Gynaecol. 2020, 127, 171-180. [CrossRef] [PubMed]

58. Liberati, A.; Altman, D.G.; Tetzlaff, J.; Mulrow, C.; Gøtzsche, P.C.; Ioannidis, J.P.; Clarke, M.; Devereaux, P.J.; Kleijnen, J.; Moher, D. The PRISMA statement for reporting systematic reviews and meta-analyses of studies that evaluate health care interventions: Explanation and elaboration. PLoS Med. 2009, 6, e1000100. [CrossRef]

59. Stroup, D.F.; Berlin, J.A.; Morton, S.C.; Olkin, I.; Williamson, G.D.; Rennie, D.; Moher, D.; Becker, B.J.; Sipe, T.A.; Thacker, S.B. Meta-analysis of observational studies in epidemiology: A proposal for reporting. Meta-analysis Of Observational Studies in Epidemiology (MOOSE) group. JAMA 2000, 283, 2008-2012. [CrossRef]

60. Wells, G.A.; Shea, B.; O'Connell, D.; Peterson, J.; Welch, V.; Losos, M.; Tugwell, P. The Newcastle-Ottawa Scale (NOS) for Assessing the Quality of Nonrandomised Studies in Meta-Analyses. Available online: http://www.ohri.ca/programs/clinical_ epidemiology / nosgen.pdf (accessed on 20 January 2021).

61. Hay, P.E.; Lamont, R.F.; Taylor-Robinson, D.; Morgan, D.J.; Ison, C.; Pearson, J. Abnormal bacterial colonisation of the genital tract and subsequent preterm delivery and late miscarriage. BMJ (Clin. Res. Ed.) 1994, 308, 295-298. [CrossRef]

62. Vaneechoutte, M.; Guschin, A.; Van Simaey, L.; Gansemans, Y.; Van Nieuwerburgh, F.; Cools, P. Emended description of Gardnerella vaginalis and description of Gardnerella leopoldii sp. nov., Gardnerella piotii sp. nov. and Gardnerella swidsinskii sp. nov., with delineation of 13 genomic species within the genus Gardnerella. Int. J. Syst. Evol. Microbiol. 2019, 69, 679-687. [CrossRef]

63. Menard, J.P.; Fenollar, F.; Henry, M.; Bretelle, F.; Raoult, D. Molecular quantification of Gardnerella vaginalis and Atopobium vaginae loads to predict bacterial vaginosis. Clin. Infect. Dis. 2008, 47, 33-43. [CrossRef] [PubMed]

64. Menard, J.P.; Mazouni, C.; Fenollar, F.; Raoult, D.; Boubli, L.; Bretelle, F. Diagnostic accuracy of quantitative real-time PCR assay versus clinical and Gram stain identification of bacterial vaginosis. Eur. J. Clin. Microbiol. Infect. Dis. 2010, 29, 1547-1552. [CrossRef] [PubMed]

65. The Nordic Cochrane Centre. Review Manager (RevMan) [Computer Program]; Version 5.3; The Nordic Cochrane Centre: Copenhagen, Denmark, 2014. 